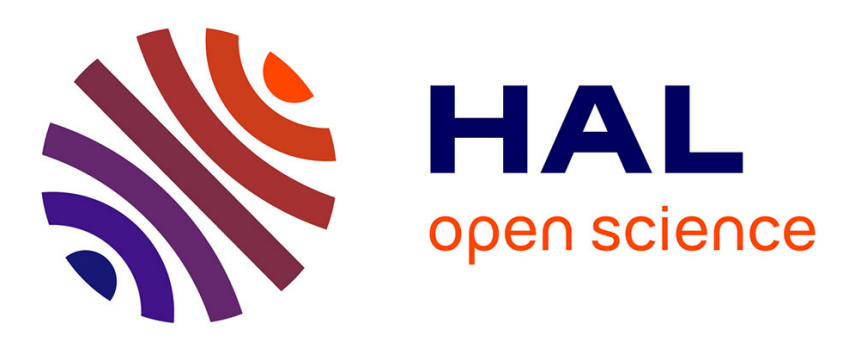

\title{
Statistical spread on the displacement damage degradation of irradiated semiconductors
}

Christophe Inguimbert, Alexandre Durand, Thierry Nuns, Kevin Lemière

\section{To cite this version:}

Christophe Inguimbert, Alexandre Durand, Thierry Nuns, Kevin Lemière. Statistical spread on the displacement damage degradation of irradiated semiconductors. Nuclear Instruments and Methods in Physics Research Section B: Beam Interactions with Materials and Atoms, 2021, 490, pp.7-17. 10.1016/j.nimb.2021.01.002 . hal-03330948

\section{HAL Id: hal-03330948 https://hal.science/hal-03330948}

Submitted on 1 Sep 2021

HAL is a multi-disciplinary open access archive for the deposit and dissemination of scientific research documents, whether they are published or not. The documents may come from teaching and research institutions in France or abroad, or from public or private research centers.
L'archive ouverte pluridisciplinaire HAL, est destinée au dépôt et à la diffusion de documents scientifiques de niveau recherche, publiés ou non, émanant des établissements d'enseignement et de recherche français ou étrangers, des laboratoires publics ou privés. 


\title{
Statistical spread on the displacement damage degradation of irradiated semiconductors
}

\author{
Christophe Inguimbert $^{\mathrm{a}, 1}$, Alexandre Durand ${ }^{\mathrm{a}}$, Thierry Nuns ${ }^{\mathrm{a}}$, Kevin Lemière $^{\mathrm{a}}$ \\ ${ }^{a}$ ONERA, Toulouse center 2 av. E.Belin 31055 Toulouse cedex, France
}

\begin{abstract}
Non Ionizing Energy Loss (NIEL) is the metric conventionally used to scale displacement damage degradation of irradiated semiconductor materials. Degradation of many electrical parameters is scaled according to this average parameter. But some deviations from NIEL scaling approach are observed from time to time. The stochastic nature of irradiation is often ignored. But, the degradation is not necessarily proportional to the average degradation level given by NIEL. The scatter of the irradiation degradation level is studied in this paper. This analysis provides some hints in order to interpret some discrepancies observed between measurements and predictions made with NIEL. Reliability of NIEL scaling method, applied to dark current degradation, is discussed for Silicon and Gallium Arsenide optoelectronic devices.
\end{abstract}

Key words - Radiative space environment, displacement damage, protons, neutrons electrons, Non Ionizing Energy Loss, semiconductor material, silicon, gallium arsenide.

\section{Introduction}

Energetic particles passing through the matter are sources of degradation for electronic devices. Protons or electrons of space environment interact with atoms' nuclei, displacing them, and producing electrically active defects, that degrade the functioning of devices used in space missions [1,2]. Fluxes of particles encountered in space are big enough to produce significant degradations, that is a matter of concern for space projects. The sensitivity of different electrical parameters of many devices has been extensively studied over the years [1-28]. The ion implantation process, widely used in semiconductor industry, has also lead to many studies [29-37]. Computer simulations have also been performed over the years to provide a scientific understanding of radiation effects in semiconductor materials [38-45]. Generally speaking, optoelectronic components are particularly sensitive to the amount of defects produced by irradiations. The increase in dark current of photodiodes is a simple example of degradation. Solar cells open circuit voltage, or short circuit current have also been extensively studied over the years [4].

The radiation induced degradation level differs from a particle type to another; or for a given type of particle, it differs from an energy to another. This is a concern for space projects operating in a complex space radiation environment involving different kind of particles with wide energy range. That makes it difficult to predict the End Of Life (EOL) characteristics of a device during a space mission. For semiconductor material, the best metric to scale irradiation degradations has been found to be the Non Ionizing Energy Loss (NIEL [46-50]) i.e. the energy deposited by unit of path of the incident particle, proportional to the number of atomic displacements. This parameter is found to be proportional to the amount of defects produced by an irradiation. Multiplied by the incident fluence $(\phi)$, it gives the Displacement Damage Dose (DDD [51]). Both DDD and NIEL depend on the nature and the energy of the incident particle (E), making them the best parameters to scale degradations related to atomic displacements. At first approximation, DDD is comparable to KERMA (Kinetic energy released per unit mass) otherwise used. The degradation level of electronic devices related to displacement damage is commonly scaled according to DDD [1,2,51]. When scaled per unit of incident fluence, according to the so called "NIEL scaling approach" [1-27], the experimentally measured degradation level can be directly compared to NIEL. When the considered degraded parameter, for instance increase in dark current $\left(\Delta \mathrm{I}_{\text {dark }}\right)$, is linear with the fluence $(\phi)$, the experimental damage factor $\left(\mathrm{K}_{\text {Dark }}\right)$, defined as the slope of the degradation by unit fluence $\left(\Delta \mathrm{I}_{\text {dark }} / \phi\right)$ is proportional to NIEL and can be directly compared to it [1]:

$K_{\text {Dark }}(E)=\frac{\Delta I_{\text {Dark }}}{\emptyset . V}(E) \propto N I E L(E)$

\footnotetext{
${ }^{1}$ Corresponding author : Christophe.Inguimbert@onera.fr
} 
where $\mathrm{V}$ is the volume of the depleted region of the device. Many damage factors are therefore directly compared to NIEL. The well-known "NIEL scaling approach" is shown to work quite well in most cases [1-14], apart from some deviations observed for electrons [15,16,28] in Si, GaAs and InGaAs, for high energy protons in GaAs [17-22] and for neutrons in GaAs [23]. Some authors also report that NIEL has to be used very carefully and is not shown to be valid for changes in depletion voltage of oxygenated and standard Silicon detectors [24]. Experimental damage factors for GaAs devices [19-21] are plotted against the proton incident energy in the Fig. 1 ([52]). The deviation from the expected value provided by NIEL (red line) is obvious.

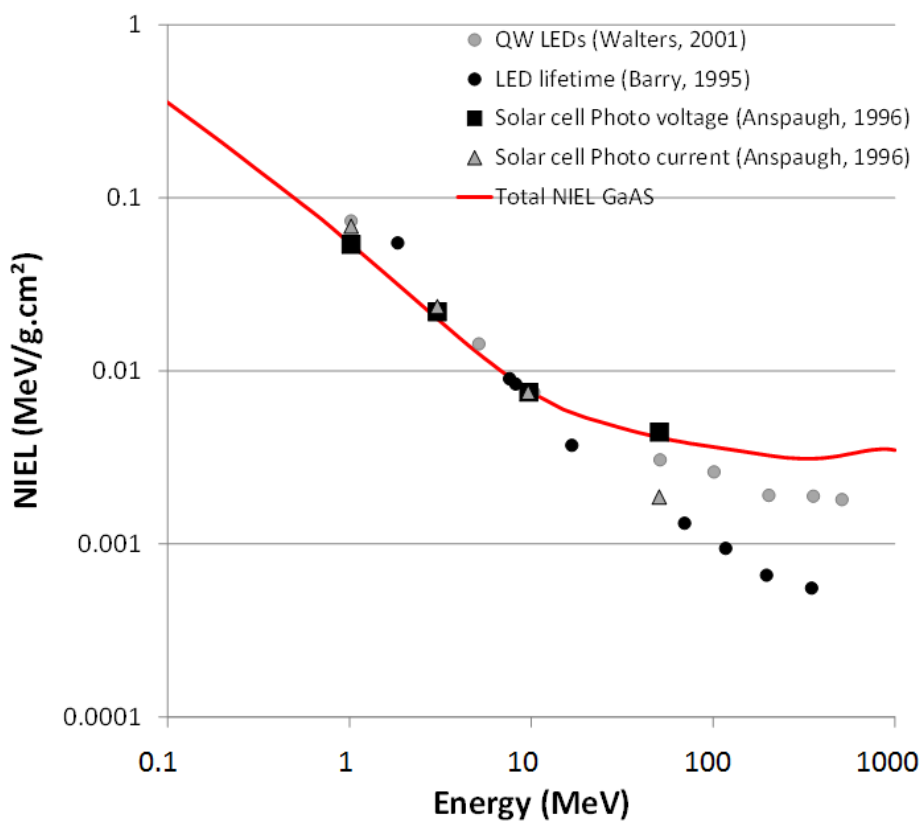

Fig. 1. GaAs damage factors coming from literature [19-21], have been reported on calculated NIEL vs. incident energy curve (red line, equation 2). Data from Barry, Anspaugh and Walters come respectively from references, [19], [20] and [21].Different damage factors coming from [19,21] are normalized according to $10 \mathrm{MeV}$ protons' NIEL. Black dots [19] show the relative degradation of LEDs minority carrier lifetime, black squares [20] represent the relative degradation of solar cells open circuit voltage, grey triangles [20] are the relative damage degradation of solar cells short circuit current, and grey dots [21] show the relative degradation of light output intensity of QW LEDs.

Some interpretations have been given in the past to explain such kind of discrepancies. In the case of the deviations illustrated in the Fig. 1, discrepancies could be attributed to large size clusters where strong annealing processes could take place. Some geometrical effects, related to the homogeneity of the degradation were also discussed [19]. But the stochastic nature of irradiation damage processes has never been addressed in detail. Nonetheless, it is important to be considered as mentioned by Nordlund [45].

This is the main goal of this work. A detailed analysis of the statistical scatter of damaging process is performed thanks to dedicated Monte Carlo calculations. This analysis provides some hints to interpret deviations from NIEL scaling laws, observed for high energy protons. After some generalities about the radiation interaction process, a brief description of the employed Monte Carlo toolkit is provided. Then, in the three following sections, the statistical spread of the damaging process is discussed in detail for respectively, protons, electrons and neutrons. Both concept of damage distribution and Dark Current Non Uniformity (DCNU) will be introduced. Eventually, the reliability of the NIEL scaling approach is discussed in terms of the presented statistical analysis.

\section{Generalities about NIEL concept}

As reminded in the introduction, for a particle of a given type and energy, the displacement damage dose (DDD) is the product of NIEL by the incident fluence $(\phi)$. It is proportional to the number of atomic displacements produced by the irradiation. It is analogous to Total Ionizing Dose (TID), which quantifies ionizing processes. The NIEL is defined as an average energy loss by unit path length according to the following integral: 


$$
\left.\operatorname{NIEL}(E)=\frac{d E}{d x}(E)=\eta \cdot \int_{Q_{\min }}^{Q_{\max }} \frac{d \sigma}{d Q}\right)_{E}(Q) \cdot Q \cdot d Q
$$

$\mathrm{d} \sigma / \mathrm{dQ}$ is the probability distribution of recoil energies. Q is the recoil energy imparted to nuclei of the medium. Equation (2) is exactly the definition of the average energy imparted to recoil particles. But, the probability of interaction with nuclei $(\sigma)$ is very low (Table 1). Along the path of an incident proton, the distance between two nuclear interactions $(1 / \sigma \eta)$ is quite large (Table 2$)$. This is very different from ionizing processes for which the mean free path is of few nanometers. Despite this low mean free path values, it is known [53] that ionizing energy loss presents some statistical distributions (straggling), which in turn induces some statistical variations of ionization in particle detectors of various dimensions. That imposes severe constraints to design of particle detection systems. In the case of nuclear interactions, this mean free path could reach, depending on the energy and the type of interactions, several millimetres (Table 2). Contrary to ionization, for which average stopping power is reliable over short distances, NIEL cannot reasonably be determined below a particle path of some tens of micrometers. In a volume, the average degradation level, proportional to NIEL, can only be reached if the number of interactions is large enough (Table 3 ) in order to allow the reliable calculation of an average.

\section{Table 1}

Proton+Si interaction cross sections for energies ranging from $1 \mathrm{MeV}$ up to $300 \mathrm{MeV}$ (Coulombian, nuclear elastic \& inelastic interactions). Calculations have been performed with NEMO code [49].

\begin{tabular}{|c|c|c|c|}
\hline & \multicolumn{3}{|c|}{ Cross sections } \\
\hline $\begin{array}{c}\mathrm{E} \\
\mathrm{MeV}\end{array}$ & $\begin{array}{c}\text { Coulombian } \\
\mathrm{cm}^{2}\end{array}$ & $\begin{array}{c}\text { nuclear elastic } \\
\mathrm{cm}^{2}\end{array}$ & $\begin{array}{c}\text { nuclear inelastic } \\
\mathrm{cm}^{2}\end{array}$ \\
\hline 1 & $2.010^{-20}$ & $4.510^{-24}$ & 0.0 \\
\hline 10 & $2.210^{-21}$ & $7.410^{-25}$ & $1.1310^{-24}$ \\
\hline 60 & $3.810^{-22}$ & $1.9510^{-24}$ & $5.910^{-25}$ \\
\hline 100 & $2.310^{-22}$ & $1.7610^{-24}$ & $5.210^{-25}$ \\
\hline 200 & $1.1510^{-22}$ & $1.0410^{-24}$ & $4.910^{-25}$ \\
\hline 300 & $8.510^{-23}$ & $9.310^{-25}$ & $4.910^{-25}$ \\
\hline
\end{tabular}

Table 2

Proton+Si interaction mean free paths for energies ranging from $1 \mathrm{MeV}$ up to $300 \mathrm{MeV}$ (Coulombian, nuclear elastic \& inelastic interaction). Calculations have been performed with NEMO code [49].

\begin{tabular}{cccc}
\hline \multicolumn{3}{c}{ Mean free path } \\
\hline $\mathrm{E}$ & $\begin{array}{c}\text { Coulombian } \\
\mathrm{mm}\end{array}$ & $\begin{array}{c}\text { nuclear elastic } \\
\mathrm{mm}\end{array}$ & $\begin{array}{c}\text { nuclear inelastic } \\
\mathrm{mm}\end{array}$ \\
\hline 1 & 0.01 & 44.84 & - \\
10 & 0.09 & 270.01 & 177.74 \\
60 & 0.53 & 102.62 & 338.23 \\
100 & 0.87 & 113.40 & 385.36 \\
200 & 1.74 & 193.06 & 402.41 \\
300 & 2.35 & 214.89 & 404.40 \\
\hline
\end{tabular}

Table 3

Average number of proton+Si interactions induced by $10^{+09}$ protons $/ \mathrm{cm}^{2}$ in a volume of $100 \mu \mathrm{m} \times 100 \mu \mathrm{m} \times 10 \mu \mathrm{m}$ (Coulombian, nuclear elastic \& inelastic interactions).

\begin{tabular}{cccc}
\hline \multicolumn{3}{c}{ Number of interactions } \\
\hline $\mathrm{E}$ & Coulombian & nuclear elastic & nuclear inelastic \\
$\mathrm{MeV}$ & 100000.0 & 22.3 & - \\
1 & 11000.0 & 3.7 & 5.6 \\
10 & 1900.0 & 9.7 & 3.0 \\
60 & 1150.0 & 8.8 & 2.6 \\
100 & 575.0 & 5.2 & 2.5 \\
200 & 425.0 & 4.7 & 2.5 \\
300 & & & \\
\hline
\end{tabular}


Three kind of particle+nucleus interactions can produce atomic displacements: Coulombian, nuclear elastic and nuclear inelastic interactions. The most probable mechanism is the long-range Coulombian interaction, which cross sections are of several hundred of Barns (Table 1). Nuclear interactions (elastic and inelastic) cross sections are rather in the order of Barn. These cross sections lead to mean free paths of respectively, hundreds of micrometers in the case of Coulombian interactions and several hundreds of $\mathrm{mm}$ for the two others interaction types (Table 2). These values, even for Coulombian interactions, remain large compared to the size of current devices. In Silicon, $100 \mathrm{MeV}$ incident proton produces in average, a Coulombian interaction each $\mathrm{mm} .1 \mathrm{MeV}$ proton produces an interaction in average each $\sim 10 \mu \mathrm{m}$. It is far smaller. But it remains quite large compared to the range of this proton which is around $\sim 16 \mu \mathrm{m}$. It means that along its whole range an incident proton of $1 \mathrm{MeV}$ will produce most of time a single interaction. This shows clearly that, under a distance of few micrometers, NIEL has no meaning for a single particle. At this scale $(\sim 10 \mu \mathrm{m})$ NIEL must be regarded as an average parameter that makes sense only for a large enough number of incident particles, producing a number of interactions sufficiently large to allow the accurate calculation of the average value of energy loss. As can be seen in Table 3 the number of nuclear interactions produced by a fluence of $10^{+09}$ protons $/ \mathrm{cm}^{2}$, in a Silicon volume of $100 \mu \mathrm{m} \times 100 \mu \mathrm{m} \times 10 \mu \mathrm{m}$, is in average lower than one. In this volume, which in itself constitutes a quite large photodiode, this low number of interactions is very inadequate to calculate properly an average number of atomic displacements (proportional to NIEL). This is not the case for Coulombian interactions which produce even at high energy a sufficient number of interactions to get a damage level representative of NIEL. This means that, depending on both the size of the sensitive region and the incident fluence, the damage level will or won't be representative of NIEL or DDD. This is especially true for nuclear (elastic \& inelastic) part of NIEL. This statistical spread is studied in more details for protons, electrons and neutrons in the rest of the paper. It has been studied thanks to Monte Carlo simulations. The damage distributions are calculated for both different fluence levels and different incident energies. Detailed calculations are performed for Silicon volumes representative of depleted regions of Si photodiodes. Some calculations have also been performed for GaAs microvolumes. The reliability of NIEL scaling approach is discussed at the end of the paper. First, a brief description of the Monte Carlo calculation is provided in the following section.

\section{Monte Carlo simulations}

The damage level of an isolated photodiode is the consequence of stochastic processes described in the previous section. This damage cannot be predicted exactly. It depends on the number of interactions (Coulombian, nuclear elastic and nuclear inelastic) occuring in the photodiode.

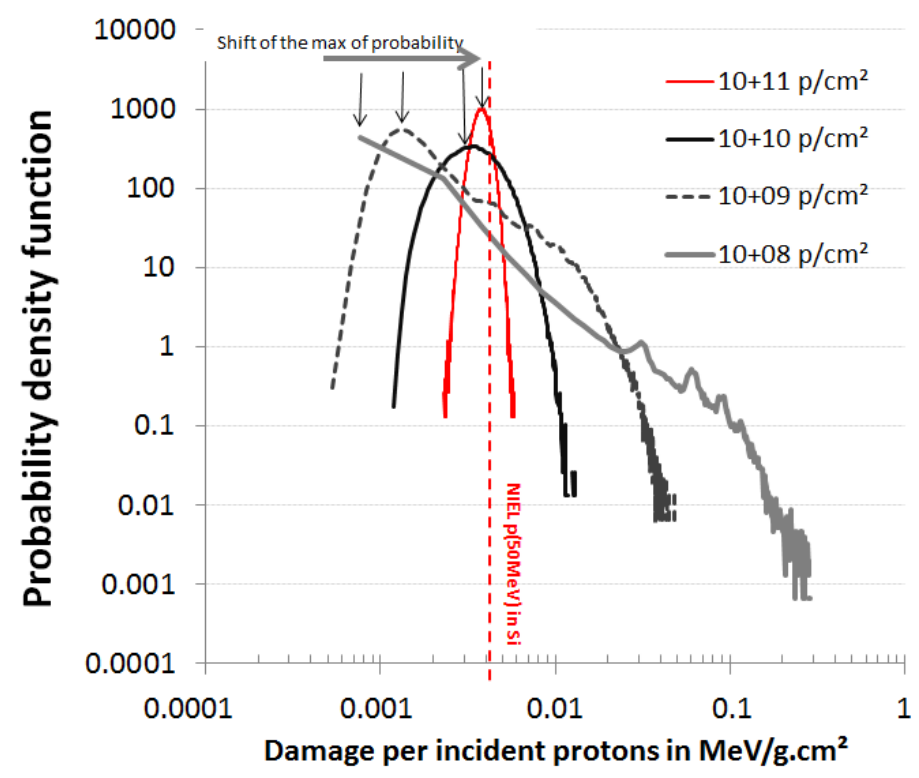

Fig. 2: Damage distribution for $50 \mathrm{MeV}$ incident protons as a function of different fluence level.

In addition, each interaction neither produces exactly the same number of atomic displacements, increasing the statistical spread. The number of interactions is driven by a Poisonian process that can be simulated thanks to a Monte Carlo algorithm (Fig. 3). 
A large set of identical photodiodes irradiated with a given fluence of identical particles, having the same energy will not show exactly the same degradation level. The scatter of degradation levels follows a distribution, that depends on both a Poisonian process, and on the shape of the interaction cross section which it depends (Fig. 2). These damage distributions evolve with the incident applied fluence, and depend on the type and the energy of the incident particles. They can be calculated according to a Monte Carlo algorithm [54-57]. As can be seen on the Fig. 2 it tends little by little toward a Gaussian function, whose average is defined as NIEL [55]. But the average degradation is reached only for large enough fluences [55].

The damage distribution is an interesting function commonly evaluated for image sensors radiation hardening analysis. The dark current increase, whose dispersion is called theDark Current Non Uniformity (DCNU) has been extensively studied, and over the years different numerical methods have been developed for its evaluation [54-64]. It finds a particular interest for radiation evaluation of star trackers, which functioning can be strongly disturbed by hot pixels, presenting high induced dark current [57]. In addition image sensors (Charge Coupled Devices (CCD) or Active Pixel Sensors (APS)) are particularly interesting test vehicles, which allow irradiating a large set of identical photodiodes. Employing a DCNU Monte Carlo toolkit, in order to evaluate radiation induced damage distributions, could provide interesting hints to know which degradation level could be expected when an isolated photodiode is irradiated with a given fluence.

We have developed a Monte Carlo based model [54-56] well suited for the statistical analysis proposed here. The only difference with DCNU prediction, is that here, the calculation is limited to the evaluation of distribution of damage. The dark current, which is assumed to be proportional to DDD, is simply not calculated. We thus obtain a damage distribution which average is equal to NIEL. The principle of calculation of damage distribution by this Monte Carlo toolkit can be found in references [54-56]. It can be summarized with the algorithm of Fig. 3.

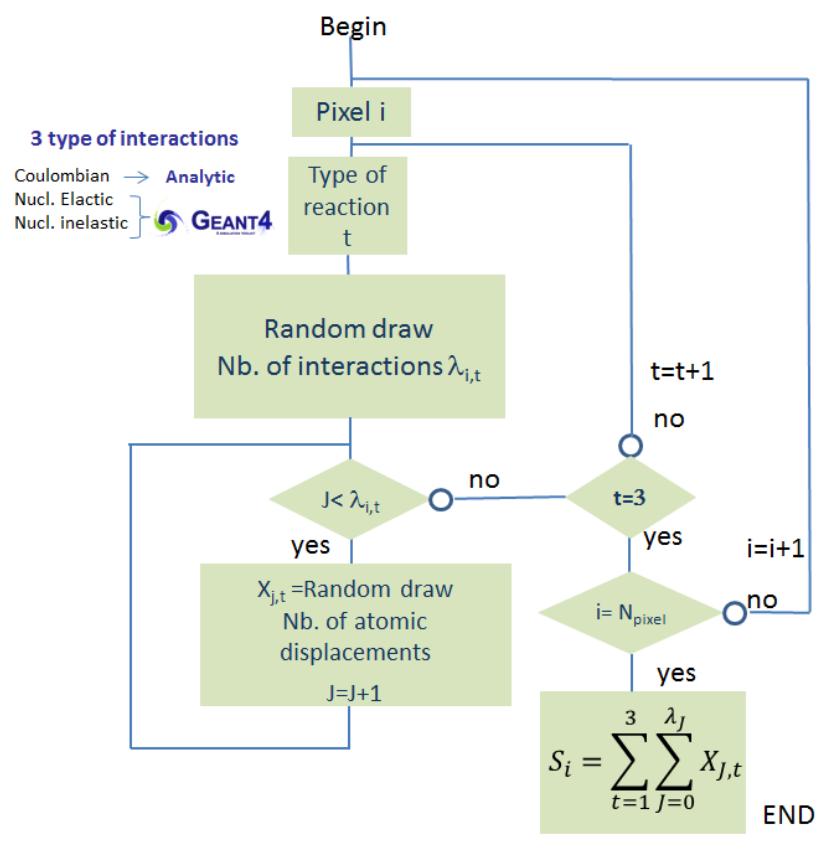

Fig. 3: Algorithm of the damage distribution calculation.

The principle is to compute the number of atomic displacements in each pixel $i$ of the irradiated array. The number of interactions of type $t$ for the pixel $\mathrm{i}, \lambda_{\mathrm{i}, t}$, is randomly drawn in a Poisonian law. The nuclear elastic, nuclear inelastic and Coulombian interactions are treated sequentially. For a given pixel, damage induced by each interaction is summed whatever their nature. The number of atomic displacements, produced by nuclear interactions (elastic, inelastic), are modelled thanks to GEANT4 Monte Carlo toolkit [51-56]. GEANT4 is a C++ library dedicated to transport of particle through matter. It offers a wide selection of physical models on a wide range of energy. The Binary cascade model of GEANT4.9.3 patch 03 has been chosen to compute nuclear interactions for both elastic and inelastic processes [65]. The 3D structure of pixels is modelled to account for border crossing effects (i.e. damage cascades getting out/in the pixel). 
A database of degraded pixels is pre-calculated with GEANT4, and called within the loop of Fig. 3. Differently, Coulombian scattering recoil nuclei are directly computed thanks to analytical cross section expressions [51-56]. Finally, the $S_{i}$ damage distribution is estimated. Dark current distribution can be estimated simply assuming proportionality between the dark current and the number of atomic displacements [51-56]. Thermal emission rate of defects can also be modelled in an improved version that also takes into account electric field enhancement effect [66]. But here, one just needs to calculate the initial damage distribution. It is shown for $50 \mathrm{MeV}$ protons for different applied fluences in Fig. 2. In the rest of the paper, these damage distributions will be represented using a color scale on mappings going from few $\mathrm{MeV}$ up to $300 \mathrm{MeV}$ (incident energy $=\mathrm{X}$ axis, damage level $=\mathrm{Y}$ axis, colour scale $=$ probability). This will allow the probability of damage to be compared with average value of NIEL (white lines on mappings). First, calculations are made for Silicon volumes. Gallium Arsenide (GaAs) volumes are also addressed during a second phase. The method has been adapted for compound materials by evaluating the number of displaced atoms of each species separately. The final number of atomic displacements is simply the sum of displaced atoms of each species.

\section{Damage distributions}

\subsection{Incident protons}

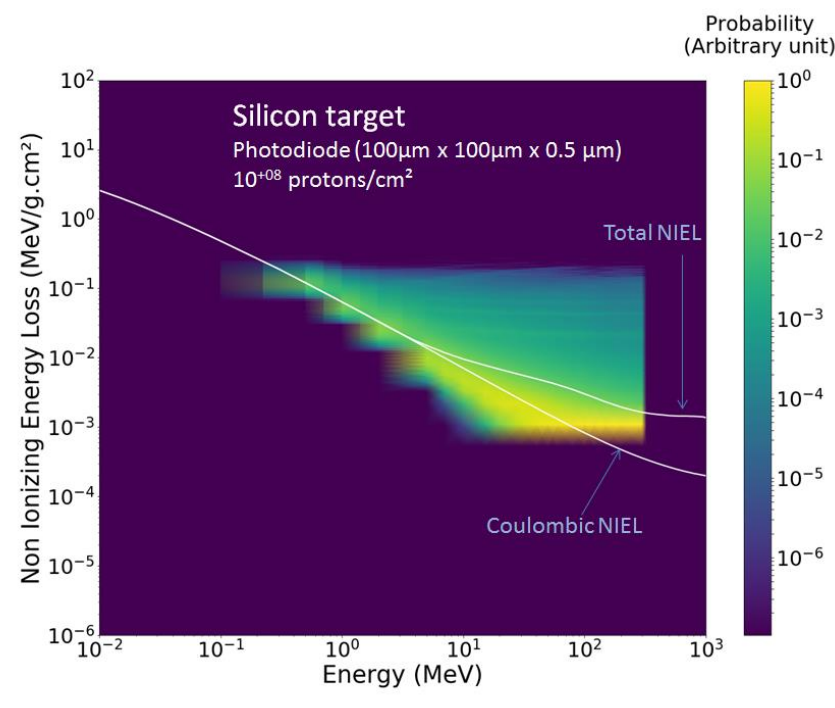

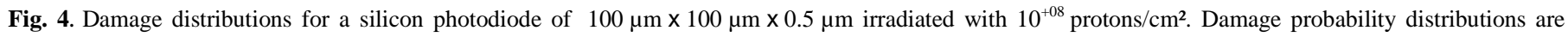

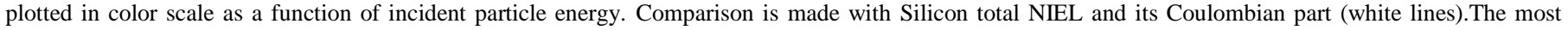
probable damage level is far lower than total NIEL.

Damage distributions of 1 million of Silicon photodiodes of $100 \mu \mathrm{m} \times 100 \mu \mathrm{m} \times 0.5 \mu \mathrm{m}$ have been calculated for incident protons ranging from $0.1 \mathrm{MeV}$ up to $300 \mathrm{MeV}$. Dimensions of simulated volumes are representative of common Silicon photodiodes. The change of these distributions has been assessed as a function of the applied incident fluence that goes from $10^{+08} \mathrm{p} / \mathrm{cm}^{2}$ up to $10^{+11} \mathrm{p} / \mathrm{cm}^{2}$ (Fig. 2, Fig. 4). Distributions obtained for $10^{+08} \mathrm{p} / \mathrm{cm}^{2}$, are mapped on Fig. 4 with a color scale. The $\mathrm{Y}$ axis represents the damage level of the distribution. It is expressed in NIEL unit $\left(\mathrm{MeV} / \mathrm{g} . \mathrm{cm}^{2}\right)$. The damage probability is distributed along a vertical column and shown in color gradient. These distributions are provided for 19 incident energies selected in a $\log$ scale in the range $[0.1 \mathrm{MeV}, 300 \mathrm{MeV}]$. The final mapping represents, on the energy range of interest, the probability to get a given damage level at a given fluence level. The dark blue represents a probability of $10^{-06}$ with a $100 \%$ uncertainty for a single count. The uncertainty for the blue sky color is in the order of few percent. Fig. 4 clearly shows that the distribution of damage can present a large width. At low fluence level $\left(<10^{+09} \mathrm{p} / \mathrm{cm}^{2}\right)$, standard deviations are comparable to the average value of these distributions (Table 4). $\sim 0.004 \mathrm{MeV} / \mathrm{g} . \mathrm{cm}^{2}$ for a $100 \mu \mathrm{m} \times 100 \mu \mathrm{m} \times 0.5 \mu \mathrm{m}$ volume irradiated with $10^{+09} \mathrm{p} / \mathrm{cm}^{2} 50 \mathrm{MeV}$ protons.

It shows that a single photodiode has actually a very low probability to be damaged at a level exactly equal to the average represented by total NIEL (actually 1 in 40 chance for $50 \mathrm{MeV}$ protons). And one can even see on this figure, that the maximum of probability is obtained for significantly lower damage level (3 times lower than the NIEL for $50 \mathrm{MeV}$ protons (Fig. 2, Fig. 4)). 
When a fluence of $10^{+09}$ protons $/ \mathrm{cm}^{2}$ is applied on this photodiode, one get 1 in 5 chance to measure a degradation level 3 times lower than value predicted by NIEL, while the chance is solely of 1 in 40 to measure a degradation level proportional to NIEL.

Table 4

Both average and maximum damage level along with the standard deviation are given for a volume of $100 \mu \mathrm{m} \times 100 \mu \mathrm{m} \times 0.5 \mu \mathrm{m}$ irradiated with $50 \mathrm{MeV}$ protons of various fluences $\left[10^{+08} \mathrm{p} / \mathrm{cm}^{2}, 10^{+11} \mathrm{p} / \mathrm{cm}^{2}\right]$.

\begin{tabular}{|c|c|c|c|c|c|}
\hline Fluence & $\mathrm{p} / \mathrm{cm}^{2}$ & $10^{+08}$ & $10^{+09}$ & $10^{+10}$ & $10^{+11}$ \\
\hline \multirow{3}{*}{$\begin{array}{l}\text { Mean } \mathrm{Nb} \text {. of } \\
\text { interactions per pixel }\end{array}$} & Coulomb & 10 & 100 & 1000 & 10000 \\
\hline & elastic & 0.05 & 0.5 & 5 & 50 \\
\hline & inelastic & 0.015 & 0.15 & 1.5 & 15 \\
\hline Mean $(\Leftrightarrow$ NIEL $)$ & $\mathrm{MeV} / \mathrm{g} . \mathrm{cm}^{2}$ & 0.0038 & 0.0039 & 0.0039 & 0.0038 \\
\hline Maximum & $\mathrm{MeV} / \mathrm{g} . \mathrm{cm}^{2}$ & 0.0005 & 0.0013 & 0.0032 & 0.0037 \\
\hline $\begin{array}{l}\text { Std. } \\
\text { deviation }\end{array}$ & $\mathrm{MeV} / \mathrm{g} . \mathrm{cm}^{2}$ & 0.0395 & 0.0040 & 0.0013 & 0.0004 \\
\hline Mean/Max & & 7.67 & 3.00 & 1.19 & 1.03 \\
\hline
\end{tabular}

As can be seen on Fig. 4, the damage is closer to Coulombian part of NIEL than to total NIEL. The fluence is low enough so that most of photodiodes are not impacted by a nuclear reaction (elastic or inelastic). Indeed the average number of nuclear interactions can be significantly lower than 1 at low fluence level (Table 3). For instance, a $\sim 10^{+08}$ protons $/ \mathrm{cm}^{2}$ fluence leads to a probability of nuclear reaction in this volume of $\sim 0.01 .99$ photodiodes in 100 will not undergo any nuclear interactions. In that case, degradation of 99 photodiodes in 100 will be proportional to Coulombian part of NIEL. The similarity with the experimental data of Fig. 1 is obvious. It shows that an irradiated device is very unlikely to depict a degradation level representative of average NIEL if the chosen applied fluence is too low. The degradation becomes comparable to NIEL for increasing fluences. Fig. 2 is a cross section of Fig. 4 at $50 \mathrm{MeV}$ (dashed line). In Fig. 2, the change of damage distribution with fluence level is shown from $10^{+08} \mathrm{p} / \mathrm{cm}^{2}$ up to $10^{+11} \mathrm{p} / \mathrm{cm}^{2}$. The damage distribution tends little by little to a Gaussian curve and becomes increasingly narrower [55]. As can be seen in Fig. 2, the maximum of probability tends progressively towards the average value of NIEL. For the simulated volume $(100 \mu \mathrm{m} \times 100 \mu \mathrm{m} \times 0.5 \mu \mathrm{m})$ the convergence to NIEL is achieved for a fluence level greater than $10^{+11} \mathrm{p} / \mathrm{cm}^{2}$.

Damage distributions are given in Fig. 4 to Fig. 6 for three different fluences $\left(10^{+08} \mathrm{p} / \mathrm{cm}^{2}, 10^{+10} \mathrm{p} / \mathrm{cm}^{2}, 10^{+11} \mathrm{p} / \mathrm{cm}^{2}\right)$.The statistical spread of the damage level is higher with increasing energies. This is the consequence of the decrease of Coulombian interaction cross sections. At low energy $(<10 \mathrm{MeV})$, degradation is dominated by the huge number of Coulombian interactions occurring in the volume. The damage level follows a Gaussian distribution centered on Coulombian NIEL. The standard deviation of this distribution is relatively small due to the high number of interactions [56].

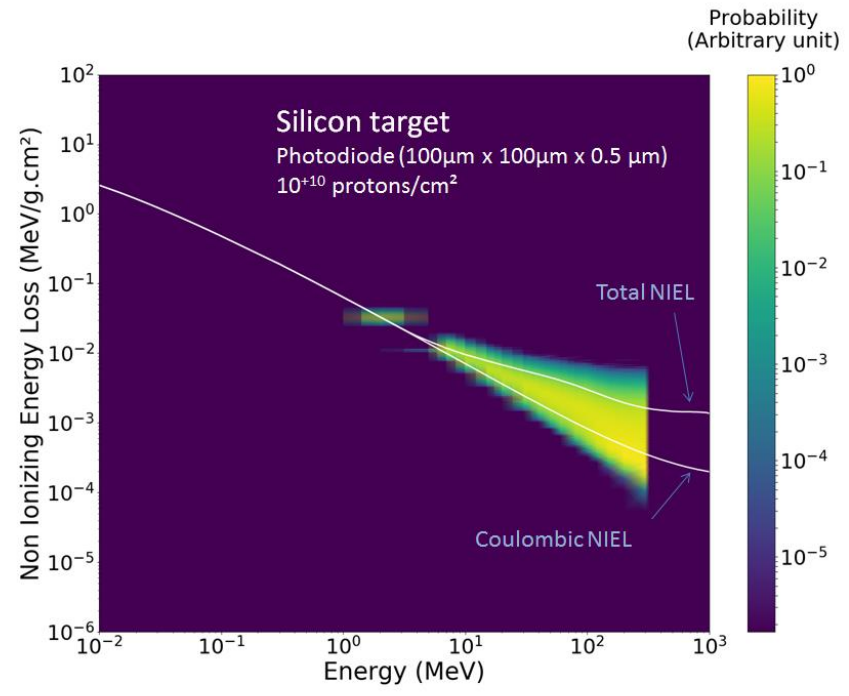

Fig. 5. . Damage distributions for a Silicon photodiode of $100 \mu \mathrm{m} \times 100 \mu \mathrm{m} \times 0.5 \mu \mathrm{m}$ irradiated with $10^{+10}$ protons $/ \mathrm{cm}^{2}$. Damage probability distributions are plotted in color scale as a function of the incident particle energy. The total NIEL and its Coulombian part are shown in white lines. The damage level is distributed homogeneously between total NIEL and its Coulombian part. 


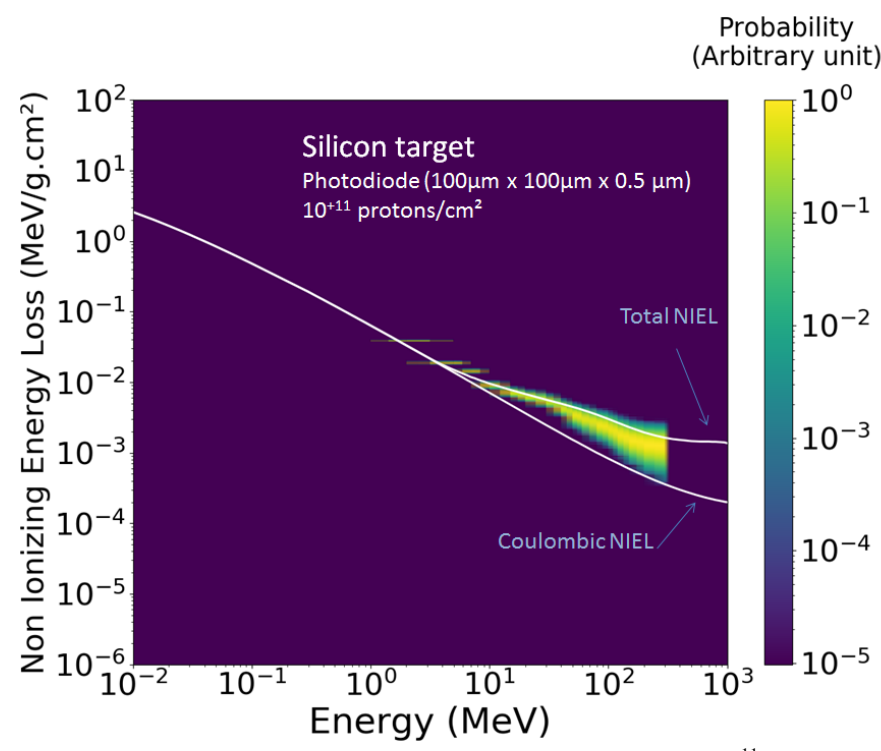

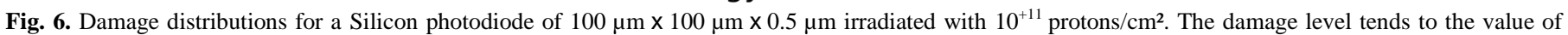
total NIEL, which corresponds to the average of the distribution.

At higher energy degradation is dominated by nuclear interactions that are able to produce at each time an important number of atomic displacements. But nuclear interaction cross sections remain relatively small, leading to a relative limited number of events, and thus to a relatively large scatter of the damage level. The overestimation of the degradation level by NIEL is due, at low fluence level, to this very low number of nuclear interactions (Table $3 \& 4$, elastic and inelastic) that prevents damage level to converge toward the average value of the distribution (i.e. nuclear NIEL). This shows that the number of nuclear interactions per sensitive volume is a fundamental parameter that has to be accounted for to evaluate properly the damaging process of a device. This value depends on both the incident fluence and dimensions of the sensitive region of the device.

According to Fig. 4 to Fig. 6, it is obvious that damage level tends with the fluence, toward average NIEL by lower values. The most probable damage level is always lower than the average damage level, because of the most important probability to get low energy recoil particles, and thus lower damage levels. Indeed, recoil energy distributions are, generally speaking and specially for Coulombian interactions, decreasing functions. Values of mean and maximum damage are provided in Table 4 for $50 \mathrm{MeV}$ incident protons on a $100 \mu \mathrm{m} \times 100 \mu \mathrm{m} \times 0.5 \mu \mathrm{m}$ photodiode. For low fluence values, NIEL can overestimate the most probable degradation level up to a factor of $\sim 8$ (fluence $10^{+08} \mathrm{p} / \mathrm{cm}^{2}$ ).

\subsection{Incident neutrons}

The case of neutrons is interesting because, they produce solely nuclear reactions. The statistical spread observed for protons, mix the contribution of two processes (Coulombian + nuclear), while for neutrons the spread in damage levels is the only consequence of nuclear processes. For the same fluence level $\left(10^{+10}\right.$ particles $\left./ \mathrm{cm}^{2}\right)$ the spread of the damage level is far higher for neutrons (Fig. 7) than for protons (Fig. 5). This is the consequence of the high number of Coulombian interactions that exist for protons and not for neutrons. Neutrons produce only nuclear (elastic and inelastic) interactions far less numerous, in the order of few units for the considered volume and fluence $\left(100 \mu \mathrm{m} \times 100 \mu \mathrm{m} \times 0.5 \mu \mathrm{m}\right.$ irradiated with $10^{+10}$ neutrons/cm ${ }^{2}$. The consequence is a very large statistical spread of the damage level (Fig. 7). A significant convergence of the damage distribution is reached for $10^{+11} \mathrm{n} / \mathrm{cm}^{2}$. As can be seen in Fig. 7 (b), at $300 \mathrm{MeV}$ the full-width half maximum of the distribution (6x10$\left.{ }^{04} \mathrm{MeV} / \mathrm{g} . \mathrm{cm}^{2}\right)$ is in the order of the mean of the distribution $\left(4 \times 10^{-04} \mathrm{MeV} / \mathrm{g} . \mathrm{cm}^{2}\right)$, while this level of convergence is reached for protons for a ten times lower fluence of $10^{+10}$ proton $/ \mathrm{cm}^{2}$ (Fig. 5). Analogously to protons, increasing the fluence reduces the standard deviation of damage distributions, which converge slowly to NIEL (Fig. 7b, Fig. 9, Fig. 10 and Fig. 11). Below 1 MeV, where elastic nuclear process dominates, this phenomenon is obvious in Fig. 9. But above $1 \mathrm{MeV}$ where nuclear inelastic reactions make the biggest contribution, the damage level seems to converge to a lower value than NIEL. This underlines another phenomenon. 


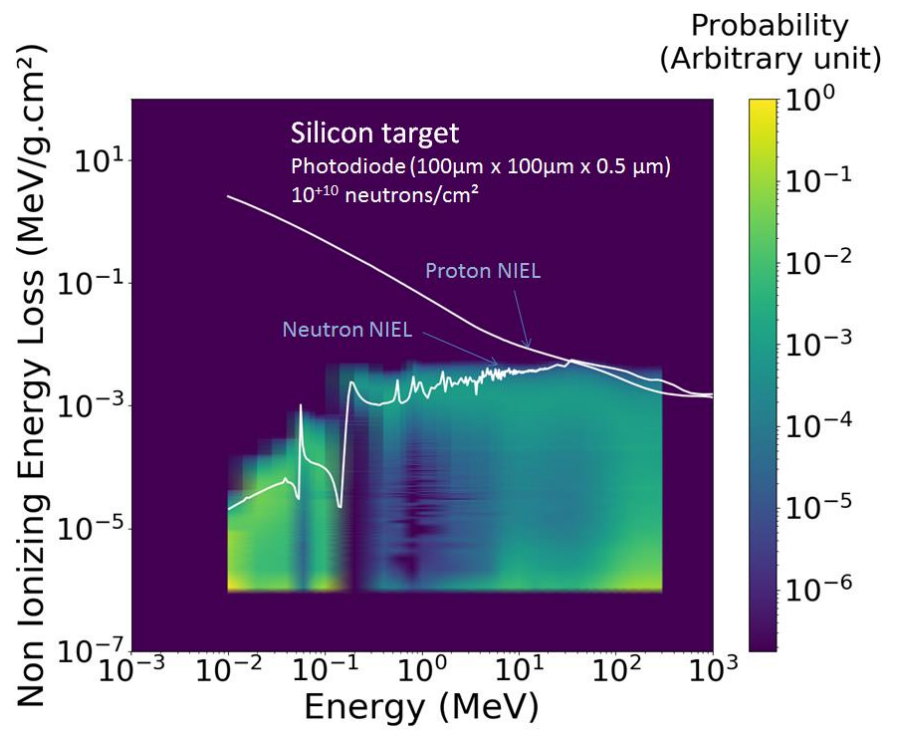

(a)

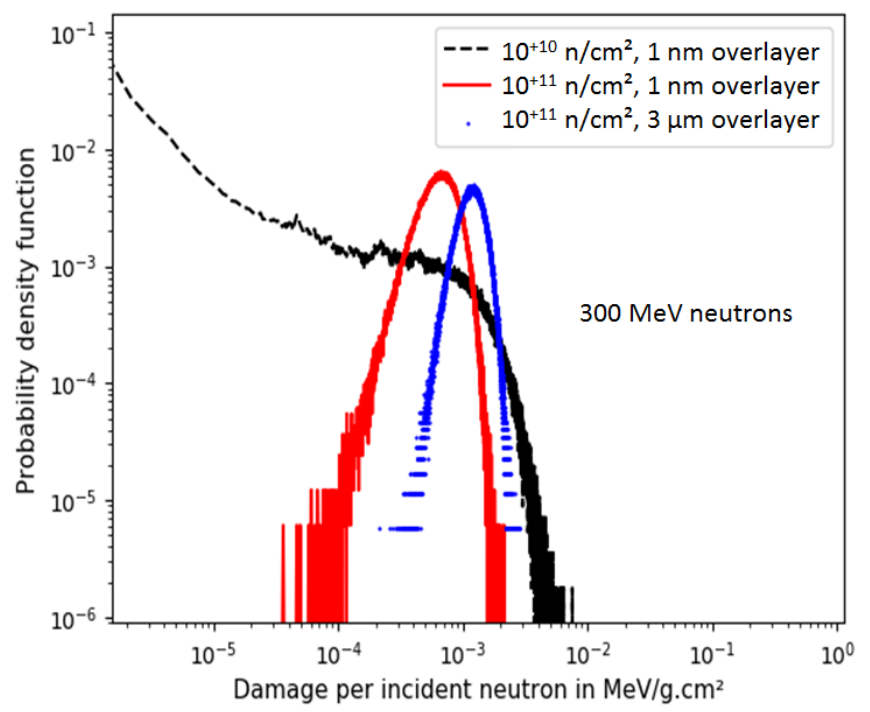

(b)

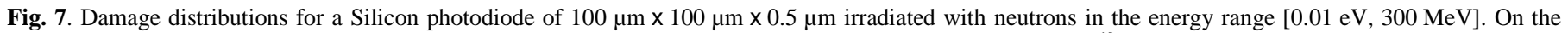

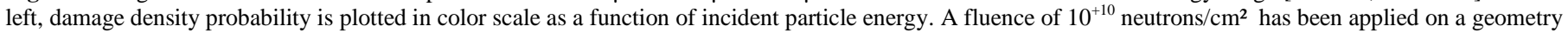

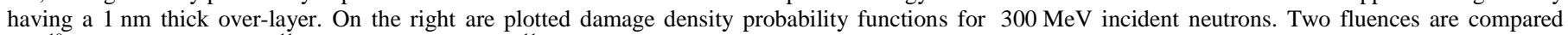

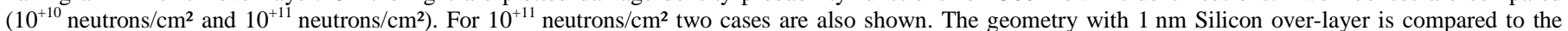
geometry having an over-layer of $3 \mu \mathrm{m}$. The thinner the over-layer is, the lower the damage level is.

During a nuclear reaction, recoil nuclei are not emitted isotropically [55]. They are mainly ejected in forward direction. In addition, their ranges are in the order of few micrometers [55]. Typically, recoil nuclei produced by $100 \mathrm{MeV}$ neutrons have average ranges of $\sim 2 \mu \mathrm{m}$. Light nuclei $(Z<6)$ can travel distances of $\sim 10 \mu \mathrm{m}$ up to $100 \mu \mathrm{m}$, while heavy nuclei $(Z>6)$ have shorter ranges in the order of few micrometers. A significant part of these heavy recoil particles can reach distances of $10 \mu \mathrm{m}$. Characteristics of these particles, in term of ranges and angular emission, have consequences on damage produced in microvolumes. Indeed, a volume can be degraded homogenously, only if it is surrounded by sufficient thickness of material. In particular, the volume must be topped by a large enough over-layer. Recoil nuclei produced in this over-layer will enter into the studied volume. The produced damage will compensate losses due to recoil nuclei that escape the volume by the rear face (Fig. 8). In the case of Fig. 7a, Fig. 9, and Fig. 10, the simulated volume is topped by a very thin layer of $1 \mathrm{~nm}$ of Silicon, too small to produce enough nuclear reactions capable to compensate losses.

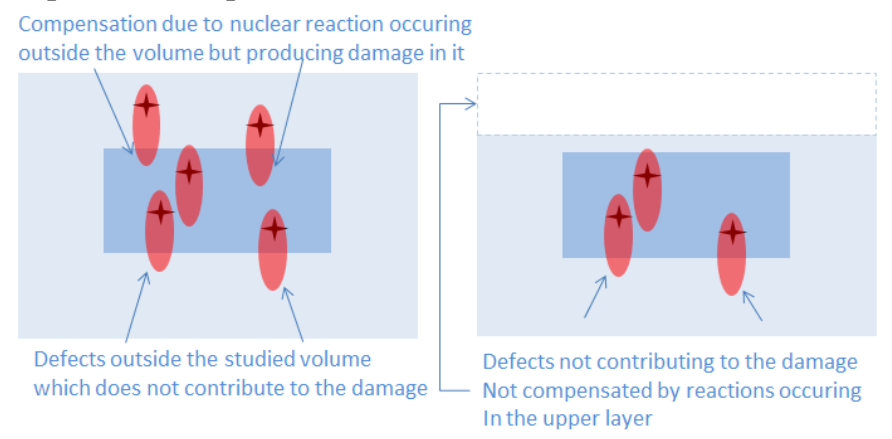

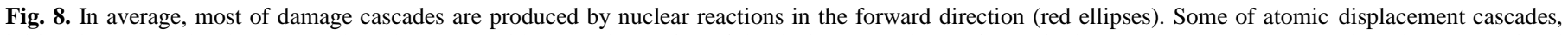

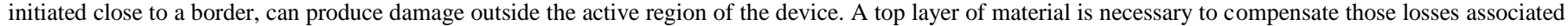
to events that get out from the sensitive volume.

The degradation cannot converge to NIEL value even at high fluence level. This phenomenon is not seen at low energy for elastic nuclear reactions that produce low energy recoils. Most of damage is produced by recoil nuclei generated in the volume. Enlarging the thickness of the over-layer from $1 \mathrm{~nm}$ to $3 \mu \mathrm{m}$ raises significantly the damage level at high energy (Fig. 7 (b), Fig. 10), making it tend closer to neutron NIEL. A larger thickness of $\sim 10 \mu \mathrm{m}$ would allow achieving the convergence toward NIEL. 
This kind of steady state phenomenon is commonly accounted for when dealing with ionizing dose effects and especially during gamma ray irradiations [67]. International test standards require the use of equilibrium material to minimize dosimetry errors. This mechanism is demonstrated here to play also a significant role in displacement damage processes. In that case the lack of over-layers on the sensitive volume (depleted region of a photodiode) can lead to an underestimation of the degradation level.

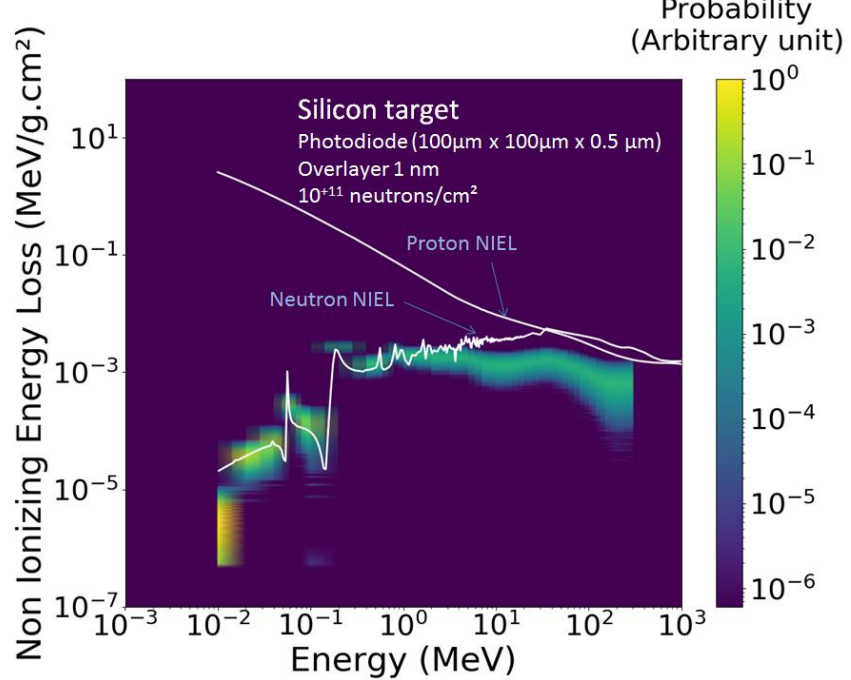

Fig. 9. Damage distributions for a Silicon photodiode of $100 \mu \mathrm{m} \times 100 \mu \mathrm{m} \times 0.5 \mu \mathrm{m}$ topped with a $1 \mathrm{~nm}$ thick overlayer. Fluence is equal to $10^{+11}$ neutrons $/ \mathrm{cm}^{2}$. Comparison is made with Silicon neutron NIEL.

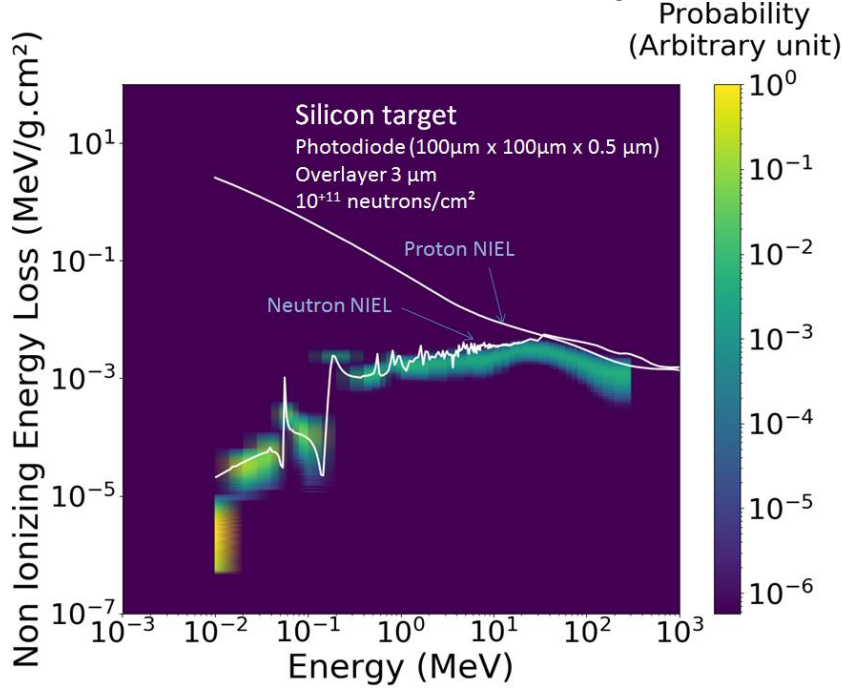

Fig. 10. Damage distributions for a Silicon photodiode of $100 \mu \mathrm{m} \times 100 \mu \mathrm{m} \times 0.5 \mu \mathrm{m}$ topped with a $3 \mu \mathrm{m}$ thick overlayer, Fluence is equal to $10^{+11}$ neutrons $/ \mathrm{cm}^{2}$. Comparison is made with Silicon neutron NIEL.

\subsection{Incident electrons}

As can be seen on following figures (Fig. 11, Fig. 12), the behavior of electrons is quite different from the case of protons and neutrons presented formerly. In our energy domain of interest electrons produce exclusively Coulombian interactions. Ddamage distribution tends regularly to the NIEL of electrons. At a fluence of $10^{+10} \mathrm{e}-/ \mathrm{cm}^{2}$ distribution is consistent with NIEL. The low value of electron NIEL might have suggested a behavior comparable to the one of protons. Actually, compared to protons, low NIEL value of electrons is not due to low cross section values, but to the low energy of elastic Silicon recoil nuclei produced by the e-+Si Coulombian interactions. For instance, a $10^{+10} \mathrm{e}-/ \mathrm{cm}^{2}$ electron fluence produces a mean value of $\sim 75$ interactions in a volume $100 \mu \mathrm{m} \times 100 \mu \mathrm{m} \times 0.5 \mu \mathrm{m}\left(\sigma_{\mathrm{e}-(\mathrm{MeV})+\mathrm{Si}}\right.$ Coulombian interactions $\left.\sim 3 \times 10^{-23} \mathrm{~cm}^{2}\right)$. This number of interactions is large enough to make the damage level converging toward the average value of NIEL.

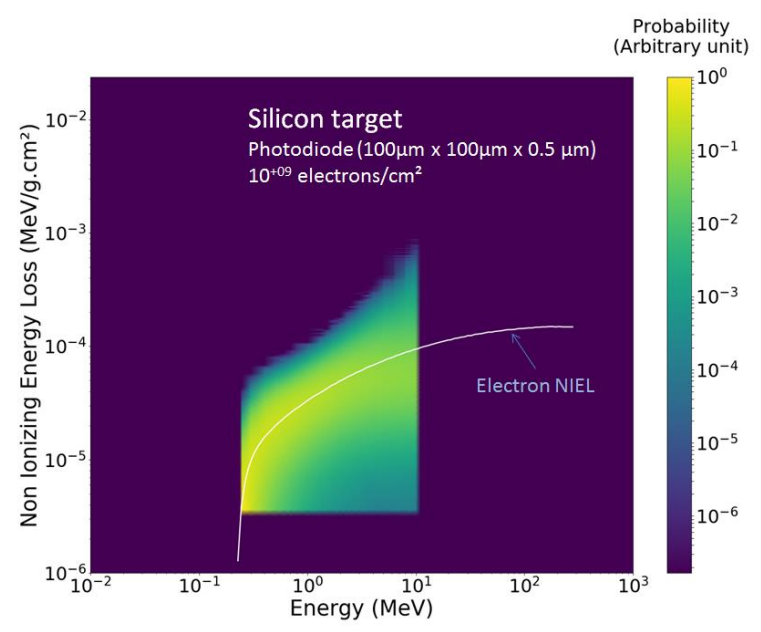

Fig. 11. Damage distributions for a Silicon photodiode of $100 \mu \mathrm{m} \times 100 \mu \mathrm{m} \times 0.5 \mu \mathrm{m}$ irradiated with $10^{+09}$ electrons $/ \mathrm{cm}^{2}$. Damage level probability is plotted in color scale as a function of incident particle energy. Comparison is made with Silicon NIEL (white line). 


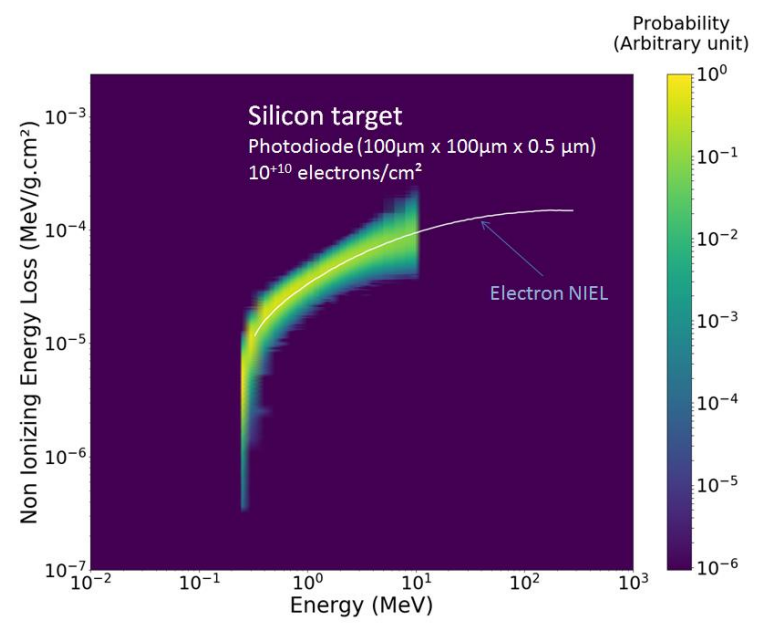

Fig. 12. Damage distributions for a Silicon photodiode of $100 \mu \mathrm{m} \times 100 \mu \mathrm{m} \times 0.5 \mu \mathrm{m}$ irradiated with $10^{+10}$ electrons $/ \mathrm{cm}^{2}$. Damage level probability is plotted in color scale as a function of incident particle energy. Comparison is made with Silicon NIEL (white line).

By decreasing the fluence down to $10^{+09}$ electrons $/ \mathrm{cm}^{2}$, the standard deviation of the damage distribution increases, but the maximum of probability remains superimposed with its average i.e. NIEL of electrons (Fig. 11). The maximum value of the distribution becomes far lower than NIEL only when the incident electron fluence reaches $10^{+08}$ electrons $/ \mathrm{cm}^{2}(0.75$ interactions in the volume). But usually, electronic devices are tested to DDD with fluences larger than $10^{+13}$ electrons $/ \mathrm{cm}^{2}$ representative of a real spatial radiation constraint. For instance, during one year spent on a geostationary orbit, a satellite will receive a total fluence of electrons having energies larger than $500 \mathrm{keV}$ close to $\sim 8 \times 10^{+13}$ electrons $/ \mathrm{cm}^{2}$ (AE8max [57]).

\section{Case of protons in Gallium Arsenide}

The statistical effect highlighted in this work is independent on the nature of materials. However, in order to compare to experimental damage measurements found in the literature, calculations have been extended to a GaAs volume $(100 \mu \mathrm{m} \times 100 \mu \mathrm{m} \times 0.5 \mu \mathrm{m})$ irradiated with incident protons. This statistical effect depends only on the average number of interactions occurring in the volume, which is a function of both applied fluence and dimensions of this volume. Calculations (not shown here) performed using a 100 times smaller volume (V/100) and a 100 times bigger fluence ( $\phi \times 100)$, lead to results identical to those obtained with the volume $\mathrm{V}$ and the fluence $\phi$. In both cases, the average number of interactions per volume remains the same. That allows a comparison with experimental measurements obtained on various devices of different dimensions.

As can be seen in Fig. 13, the convergence toward NIEL value is reached after a $10^{+11}$ protons $/ \mathrm{cm}^{2}$ fluence has been applied. This is comparable to the case of Silicon. Interaction cross sections of $\mathrm{Si}$ and $\mathrm{GaAs}$ are in the same order of magnitude. $100 \mathrm{MeV}$ proton Coulombian, nuclear elastic and inelastic interaction cross sections are respectively for Ga atoms: $\sigma_{\mathrm{CoulGa}}=9.3 \times 10^{-22} \mathrm{~cm}^{2}$, $\sigma_{\text {ElaGa }}=3.11 \times 10^{-24} \mathrm{~cm}^{2}, \sigma_{\text {IneGa }}=8.7 \times 10^{-24} \mathrm{~cm}^{2}$. These cross sections are slightly higher than those of silicon material (Table 1). The atomic density of both materials are also comparable $\left(5.10^{+22} \mathrm{Si}\right.$ atoms $/ \mathrm{cm}^{3}, 4.44 \times 10^{+22}$ atoms $/ \mathrm{cm}^{3}$ in GaAs).

As can be seen in Fig. 14, the spread of data is far more important for a fluence of $10^{+10}$ protons $/ \mathrm{cm}^{2}$. With this fluence level an average of $\sim 5$ nuclear (elastic+inelastic) interactions has been produced in the $100 \mu \mathrm{m} \times 100 \mu \mathrm{m} \times 0.5 \mu \mathrm{m}$ GaAs volume, which is too low to get a tight distribution with a quite small standard deviation. It is interesting to note that the statistical spread of experimental data [19-21] presented in Fig. 1 is consistent with the probability distribution calculated by the Monte Carlo method (Fig. 14). 


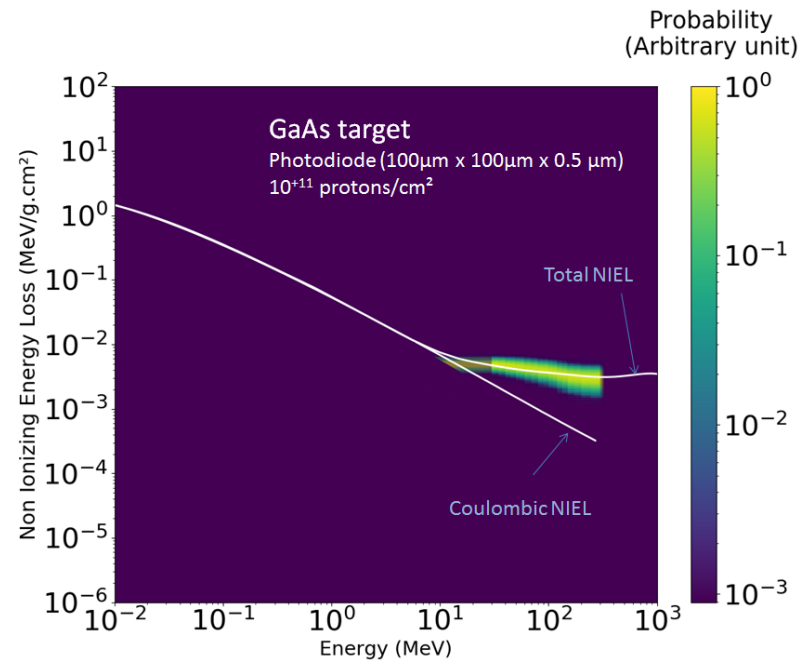

Fig. 13. Damage distributions for a GaAs photodiode of $100 \mu \mathrm{m} \times 100 \mu \mathrm{m} \times 0.5 \mu \mathrm{m}$ irradiated with $10^{+11}$ protons/cm². Damage distribution probability is plotted in color scale as a function of incident particle energy. At this dose level convergence toward GaAs total NIEL is achieved.

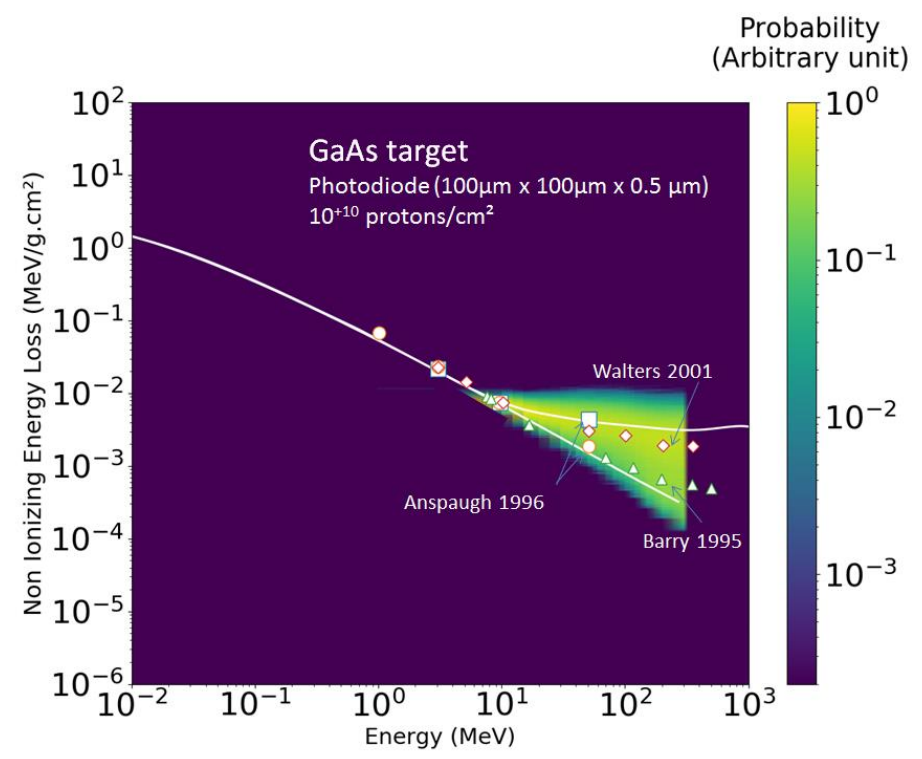

Fig. 14. Damage distributions for a GaAs photodiode of $100 \mu \mathrm{m} \times 100 \mu \mathrm{m} \times 0.5 \mu \mathrm{m}$ irradiated with $10^{+10}$ protons $/ \mathrm{cm}^{2}$. Damage distribution probability is plotted in color scale as a function of incident particle energy. Damage level is homogeneously distributed between total GaAs NIEL and its Coulombian part. Experimental data obtained in GaAs devices [19-21] and presented in Fig. 1 are reported here for a qualitative comparison. Similarities between calculation and experimental data is obvious.

Let's push further the analysis of the data from Walters et al [21]. This paper gathers their own measurements of the degradation of the light output intensity of GaAs LEDs, with data of two other references [19,20]. There are the open circuit voltage and the short circuit current degradation measurements performed by Anspaugh [20] on GaAs/Ge solar cells. There is also the lifetime damage constant measured by Barry et al. [19] in GaAs LEDs. The most interesting data are this latter from Barry et al., because they have been performed with relatively low fluence levels, ranging from $5 \times 10^{+08} \mathrm{p} / \mathrm{cm}^{2}$ up to $6 \times 10^{+09} \mathrm{p} / \mathrm{cm}^{2}$. According to our work, an overestimation of experimental data by total NIEL is expected for these set of data. Dimensions of the sensitive volume of the LED are not provided, but dimensions of this "old" technology are expected to be in the same order of magnitude as those used in our calculations. According to this hypothesis the experimental data are more likely expected to follow coulombian NIEL than total NIEL. And this is what is observed in Fig. 14.

On his side, Walters [21] used InGaAs quantum well emitting diode having a sensitive volume of $460 \mu \mathrm{m} \times 260 \mu \mathrm{m} \times 0.07 \mu \mathrm{m}$, 6 times smaller than the volume used in our calculations. According to calculations, the convergence of the damage factor to total NIEL could be expected with a fluence of $\sim 6 \times 10^{+11} \mathrm{p} / \mathrm{cm}^{2}$. As can be seen on Fig. 14, the damage factor is not so far from the total GaAs NIEL. The measurements have been performed up to $10^{+13} \mathrm{p} / \mathrm{cm}^{2}$. In that sense the damage factor is expected to be close to total NIEL. However, the extraction of this damage factor depends closely on how the fitting procedure is applied. If the adjustment of the damage vs. fluence function is optimized to best fit the low fluence part of this curve, the damage factor could be slightly underestimated. 
For Solar cells, the damage factor extraction procedure is similar to the one of the light output intensity for LEDs. It depends on how the damage vs. fluence curve is adjusted. As the active region of GaAs solar cells can be quite large, the damage factor is expected to follow total NIEL. But it was not possible to find an enough detailed description of data of Anspaugh [20] to draw any clear conclusion. In conclusion, most of these data seems to be consistent with the statistical analysis proposed here.

\section{Discussion}

This work first highlights the fact that NIEL, which is commonly used to scale the displacement damage induced degradation in electronic devices, might lack of precision in some cases, because this mean parameter does not take into account the stochastic nature of damaging process. For instance, the scatter of damage observed for proton irradiated GaAs devices is consistent with the damage probability of Fig. 14, and might be interpreted as a simple statistical spread. However, some other effects may explain these observations for high energy protons (Fig. 1, Fig. 14) [2,68]. It has been shown that higher energy protons $(\mathrm{E} \geq 10 \mathrm{MeV})$ could introduce very active recombination centers that are electrically and structurally different than those produced by lower energy protons. Energetic particles can produce clusters of defects, changing some electronic properties of irradiated devices as compared to effects of isolated defects [2]. Clusters of defects may consists of amorphous pocket regions or may present high concentrations of bond defects, leading to different recombination rates, and thus different final damage levels $[2,45]$. Both dopant and impurity types with their respective concentrations are also sensitive parameters. NIEL scaling approach is more debatable for electrical parameters such as recombination-lifetime exhibiting several functional dependences (injection level, resistivity...)[2]. Thus, several cautions must be taken when implementing NIEL scaling in practice. The fact that NIEL does not take into account the statistical spread of damaging process is another one.

This kind of statistical effect is well known for ionization process. In radiation sensors, the shift of the most probable ionization value with respect to the sensor thickness or to the applied fluence has been extensively studied in the particle accelerator community [24,53] (and references therein). The phenomenon shown here is analogous but applied to displacement damage effects. This dispersion can be the result of two different mechanisms. It can simply be due to a too low average number of interactions per pixel at low fluence level. The fluence level at which the degradation converges toward NIEL depends of course on the dimensions of the irradiated volume. The statistical spread can also be regarded as an issue related to the homogeneity of the damage dose. The steady homogeneous degradation of the depleted region of a device can be reached only if the sensitive volume is buried at a sufficient depth. Otherwise, the damage cascade escaping the volume by its rear face cannot be compensated by those entering this volume through the upper layer (cf. section, V \& Fig. 8). The consequence is a degradation level lower than the value predicted by NIEL (Fig. 9, Fig. 10). This effect is significant for smaller volumes having dimensions less than the average range of recoil nuclei $(\sim 5 \mu \mathrm{m}$ for nuclear interactions). Generally speaking, sensitive regions of GaAs devices are significantly smaller than for Silicon devices. That could explain, the more preferably observation, of underestimate damage factors in GaAs than in Silicon. The physical mechanism highlighted here is of course expected to be more important for smaller devices. The progressive scale reduction of devices could lead this effect to become dominant and thus diminishing the relevance of NIEL parameter. In addition, as we have seen in section 4, when dimensions become in the order of the ranges of recoil nuclei $(<10 \mu \mathrm{m})$, the deviation from NIEL can be enhanced by the presence or not of a thick over-layer.

This statistical effect can be observed during experiments when no attention is paid to the chosen applied fluence level. But from a more practical point of view, one might also question the importance of this mechanism for onboard devices. The first thing to underline is that NIEL remains a worst case and thus qualification methods based on NIEL are conservative. Let us take a photodiode with typical dimensions of those of a CCD: $13 \mu \mathrm{m} \times 7.5 \mu \mathrm{m} \times 6 \mu \mathrm{m}$ (CCD4720 e2v [69]). Now, let us assume that this device remains 10 years on the Low Earth Orbit (LEO) of JASON satellite (1336 km altitude, $66^{\circ}$ inclination) shielded by few centimeters of aluminum [54]. In that case, the total received fluence $\left(\sim 5 \times 10^{+10} \mathrm{p} / \mathrm{cm}^{2}\right)$ [54] gives a quite small average number of nuclear interactions per photodiode. On average, $\sim 2.5$ (1 nuclear elastic +1.5 nuclear inelastic) nuclear interactions are produced by protons of nearly $\sim 60 \mathrm{MeV}$. The most probable degradation level is estimated to be half of the NIEL value. In that case, NIEL is not suited to predict the final damage level. The lack of accuracy of NIEL will be smaller for less shielded devices for two reasons. The level of fluence is higher, reducing naturally the statistical spread. The average energy of particles crossing the device will also be lower. In that case, degradation will be dominated by low energetic particles for which nuclear interactions play a minor part. The statistical effect may be more a concern for missions facing harsher environment, such as Jovian missions, presenting an important population of energetic protons.

In space, importance of the homogeneity of damage degradation is another question. The underestimation of the degradation related to the presence or not of an over-layer on the sensitive volume is less acute in space, where irradiation is isotropic compared to experiments performed with normal incident beams. Our calculations, performed with normal incident particles, entering the sensitive region by the upper-face covered with a quite thin over-layer, are not exactly representative of space environment. This specific condition is a kind of worst case that reinforces the role of the upper-layer. Indeed, in space, particles do not penetrate the sensitive region solely by the upper-face, but they come also from lateral and back sides of the device, which naturally makes the irradiation more homogenous. In addition electronic devices are shielded naturally by the structure of the 
satellites, which changes the shape of the incident energy spectrum and the role of secondary particles in formation of the damage distribution [70]. On orbit, that will tend to minimize the mechanisms described here.

For neutrons that do not produce any Coulombian interactions, the statistical effect is by nature more obvious. According to the used geometry, above $1 \mathrm{MeV}$, degradation is overestimated by NIEL even with a fluence of $10^{+11}$ neutrons/cm ${ }^{2}$ (Fig. 10). This is due in particular to the fact that it is difficult to get a steady damage level, because of the high energy of nuclear reactions recoil nuclei. Degradation of any device not topped with a relatively thick over-layer will be systematically lower than the value predicted by NIEL. This effect, quite important for neutrons can affect any physical parameter related to the surface of the material (shallow depleted regions in ICMOS, surface conductivity of materials...). Some deviations from the NIEL scaling approach are reported even in the ASTM E722-14 neutron test standard [71]. For incident neutrons in GaAs material, the Lindhard energy partition function [72] is corrected by a damage efficiency that reduces beyond $0.1 \mathrm{MeV}$ the value of NIEL (KERMA) [71]. This behavior presents some similarities with results of Fig. 9 for which at high energy, NIEL overestimates the experimentally measured damage factors.

In this work, the amount of damage estimated by MC calculations is based on the classical theory of damage production. The number of atomic displacements produced by a recoil nucleus is given by the Lindhard energy partition function [72], which lays on Binary Cascade Approximation (BCA). But the damage produced in cascading regions introduces different kinds of defects which can also influence the degradation of electrical parameters. This is observed in case of electrons, which experimentally measured damage factors often deviate from NIEL predictions [25,73]. More informative data of defects structure can be obtained by Molecular Dynamic (MD) calculations. These simulations include the crystalline structure of the device material, which is not considered in MC calculations. Moreover, defects created by recoils with energies less than the threshold energy are only obtained by MD calculations. MD simulations can be used to reformulate the energy partitioning, including sub-threshold damage effects [25,73]. But these mechanisms are neglected in this work. One can see in Fig. 11 and Fig. 12 that calculated damage levels tend toward "classical" NIEL at high fluences.

Reliability of NIEL scaling approach will become more and more debatable for more integrated technologies having smaller sensitive regions. Engineers that conduct electronic devices qualifications need to ensure that the applied fluences are compatible with the definition of NIEL before any extrapolation using this parameter. The size of the sensitive region of devices and the level of fluence of the mission have to be accounted for. For typical photodiodes of several thousands of $\mu \mathrm{m}^{3}$, the minimum fluence to be applied to get degradation consistent to NIEL is something in the order of $10^{+10} \mathrm{p} / \mathrm{cm}^{2}$. In the case in which the radiation level of the mission becomes too small, NIEL loses its relevance and another parameter such as the Most Probable Non Ionizing Energy Loss (NIEL ${ }_{M P}$ ) could be defined and used instead of NIEL. This later parameter could be gainfully used with the standard deviation of the deposited energy, within confidence level methods, to increase the reliability of qualification procedures. These parameters can be deduced from damage distributions presented in this work. This may be the subject of further work.

\section{Conclusion}

For an irradiated volume of a given size, if the induced number of nuclear interactions is too low, the final degradation will not be proportional to the expected value of NIEL. Displacement damage factors are thus demonstrated to depend on the applied fluence. The degradation follows a distribution whose standard deviation increases with the decreasing applied fluence. The most probable degradation level can be significantly lower than the average damage level given by NIEL. It is known that cautions must be taken when using NIEL scaling approach. Measured degradations may deviate from NIEL values for many reasons. It depends on materials' parameters (doping, impurities, ...), nature of produced defects (isolated defect, clusters...), the functional dependence of measured electrical parameters. But this work shows also that it depends on the applied fluence. Some deviations observed from NIEL scaling law for both energetic protons and neutrons, seems to be consistent with uncertainties related to the stochastic nature of damaging process.

Even if NIEL is demonstrated to remain a worst case, this stochastic effect will become increasingly important with the reduction in size of devices. Space projects can gain margins using more reliable degradation scaling methods. The Most Probable Non Ionizing Energy Loss (NIEL ${ }_{\mathrm{MP}}$ ) parameter, in conjunction with confident level methods based on damage standard deviation, could alternatively be employed.

\section{References}

[1] J. R. Srour, Review of displacement damage effects in silicon devices, IEEE Trans. Nucl. Sci. 50 (3) (2003) 653-670.

[2] J. R. Srour, J. W. Palko A framework for understanding displacement damage mechanisms in irradiated silicon devices, IEEE Trans. Nucl. Sci. 53 (6) (2006) 3610-3620.

[3] G. P. Summers et al., Correlation of Particle-Induced Displacement Damage in Silicon, IEEE Trans. Nucl. Sci. 34 (6) (1987) 1133-1139.

[4] S. R. Messenger et al., Modeling solar cell degradation in space: A comparison of the NRL displacement damage dose and JPL equivalent fluence approaches, Progress in Phot.: Res. and Appl. 9, (2001) 103-121.

[5] K. Thommen, Recovery of low temperature electron irradiation-induced damage in n-type GaAS, Radiation effects 2 (3) (1970) 201-210 
[6] A. H. Kalma, R. A. Berger, C. J. Fischer, and B. A. Green, Energy and temperature dependence of electron irradiation damage in GaAs, IEEE Trans. Nucl. Sci. 22 (6) (1975) 2277-2282.

[7] D. Pons, P. M. Mooney, and J. C. Bourgoin, Energy-dependence of deep level introduction in electron-irradiated GaAs, J. Applied Phys. 51 ( 6) (1980) 2038-2042

[8] M. Yamaguchi, C. Amano, ${ }^{60}$ Co $\gamma$-ray and electron irradiation damage of GaAs single crystals and solar cells, J. Applied Phys. 54 (9) (1983) 5021-5029

[9] A. Meulenberg et al., Dosimetry and total dose radiation testing of GaAs devices, IEEE Trans. Nucl. Sci.34 (6) (1987) 1745-1750

[10] M. A. Xapsos et al., Co60 Gamma Ray and Electron Displacement Damage Studies of Semiconductors, IEEE Trans. Nucl. Sci.41 (6) (1994) 1945-1949.

[11] G. P. Summers et al., Damage correlations in semiconductors exposed to gamma, electron and proton radiations, IEEE Trans. Nucl. Sci. 40 (6) 1993 13721379.

[12] G. P. Summers, E. A. Burke, and M. A. Xapsos, displacement damage analogs to ionizing radiation effects, Rad. Meas. 24 (1) (1995) 1-8.

[13] J. H. Warner et al., Correlation of electron radiation induced damage in GaAs solar cells, IEEE Trans. Nucl. Sci. 53 (4) (2006) 1988-1994.

[14] J. H. Warner et al., A comparison between $p+n$ and $n+p$ GaAs displacement damage coefficients following proton irradiation, Proceedings of the 33th International IEEE Conference on Photovoltaic Specialists, (2008) pp.1-5.

[15] P. Arnolda, C. Inguimbert, T. Nuns, C. Boatella-Polo, NIEL scaling: comparison with measured defect introduction rate in silicon, IEEE Trans. Nucl. Sci., 58 (3) (2011) 756-763.

[16] E. El Allam, C. Inguimbert, T. Nuns, A. Meulemberg, A. Jorio, I. Zorkani, Gamma and Electron NIEL Dependence of Irradiated GaAs, IEEE Trans. Nucl. Sci., 64 (3) (2017) 991-998.

[17] E. A. Burke; C. J. Dale; A. B. Campbell; G. P. Summers; W. J. Stapor; M. A. Xapsos; T. Palmer; R. Zuleeg, Energy Dependence of Proton-Induced Displacement Damage in Gallium Arsenide, IEEE Trans. Nucl. Sci., 34 (6) (1987) 1220-1226.

[18] G. P. Summers, E. A. Burke, M. A. Xapsos, C. Dale, P. W Marshall, E. L. Petersen, Displacement damage in GaAs structures, IEEE Trans. Nucl. Sci., 35 (6) (1988) 1221-1226.

[19] A. L. Barry, A. J. Houdayer, P. F. Hinrichsen, W. G. Letourneau, and J. Vincent, The energy dependence of lifetime damage constants in GaAs LED's for 1-500 MeV protons, IEEE Trans. Nucl. Sci., 42 (6) (1995) 2104-2107.

[20] B. E. Anspaugh., GaAs Solar Cell Radiation Handbook, JPL Publication 96-9 (1996).

[21] R. J. Walters, S. R. Messenger, G. P. Summers, E. A. Burke, S. M. Khanna, D. Estan. L. S. Erhardt, H. C. Liu, M. Gao, M. Buchanan, A. J. SpringThorpe, A. Houdayer, and C. Carlone, Correlation of Proton Radiation Damage in InGaAs-GaAs Quantum-Well Light-Emitting Diodes, IEEE Trans. Nucl. Sci., 48 (6) (2001) $1773-1777$.

[22] S. R. Messenger, R. J. Walters, E. Burke, G. P. Summers, and M. A. Xapsos, NIEL and damage correlations for high-energy protons in gallium arsenide devices, IEEE Trans. Nucl. Sci., 48 (6) (2001) 2121-2126.

[23] A. M. Ougouag, J.G. Williams, M. B. Danjaji, J. L. Yang, J. L. Meason, Differential displacement kerma cross sections for neutron interactions in Si and GaAs, IEEE Trans. Nucl. Sci., 37 (6) Part II (1990) 2219-2228.

[24] M. Moll, Displacement Damage in Silicon Detectors for High Energy Physics, IEEE Trans. Nucl. Sci., 65 (8) (2018) 1561-1582.

[25] C. Inguimbert, P. Arnolda, T. Nuns, and G. Rolland, Effective NIEL in silicon: Calculation using molecular dynamic results, IEEE Trans. Nucl. Sci., 57 (4) (2010) 1915-1923.

[26] M. El Allam, C. Inguimbert, T. Nuns, A. Meulenberg, A. Jorio, I. Zorkani, Gamma and Electron NIEL Dependence of Irradiated GaAs IEEE Trans. Nucl. Sci., 64 (3) (2017) 991-998.

[27] M. El Allam, C. Inguimbert, A. Meulenberg, A. Jorio, I. Zorkani, Gamma non-ionizing energy loss: Comparison with the damage factor in silicon devices J. of Appl. Phys., 123 (2018) 095703.

[28] T. Nuns, C. Inguimbert, J.Barbero, J. Moreno, S. Ducret, A. Nedelcu, B. Galnander, E. Passoth Displacement damage effects in InGaAs photodiodes produced by electrons, protons and neutrons irradiations IEEE Trans. Nucl. Sci. (2020) DOI 10.1109/TNS.2020.2984133.

[29] O.W. Holland, J. Narayan, D. Fathy, Ion beam processes in Si, Nucl. Instrum. Meth. B 7 (1985) 243-250.

[30] J. Linnros, G. Holmen, Dose rate dependence and time constant of the ion beam-induced crystallization mechanism in silicon, J. Appl. Phys. 62 (12) (1987) 4737.

[31] R.D. Goldberg, R.G. Elliman, J.S. Williams, The kinetics of self ion amorphization of silicon, Nucl. Instrum. Meth. B 80/81 (1993) 596-599.

[32] I. Jencic, I.M. Robertson, Low-energy electron beam induced regrowth of isolated amorphous zones in Si and Ge, J. Mater. Res. 11 (9) (1996) $2152-2157$.

[33] H. Hensel, H.M. Urbassek, Implantation and damage under low energy Si self-bombardment, Phys. Rev. B 57 (13) (1997) $4756-4763$.

[34] J.S. Williams, Ion implantation of semiconductors, Mater. Sci. Eng. 253 (1-2) (1998) 8-15.

[35] M.W. Bench, I.M. Robertson, M.A. Kirk, I. Jencic, Production of amorphous zones in GaAs by the direct impact of energetic heavy ions, J. Appl. Phys. 87 (2000) 49-56.

[36] C.J. Glover, M.C. Ridgway, A.P. Byrne, K.M. Yu, G.J. Foran, C. Clerc, J. Lundsgaard Hansen, A. Nylandsted Larsen, Micro-and macro-structure of implantation-induced disorder in Ge, Nucl. Instrum. Meth. B 161 (2000) 1033-1037.

[37] E. Wendler, A. Kamarou, E. Alves, K. Gartner, W. Wesch, Three-step amorphization process in ion-implanted GaN at 15 K, Nucl. Instrum. Meth. B 206 (2003) 1028-1032.

[38] L.A. Marques, M.J. Caturla, H. Huang, T. Diaz de la Rubia, Molecular dynamics studies of the ion beam induced crystallization in silicon, Mater. Res. Soc. Symp. Proc. 396 (1994) 201.

[39] M.J. Caturla, T. Diaz de la Rubia, G.H. Gilmer, Recrystallization of a planar amorphous-crystalline interface in silicon by low energy recoils: a molecular dynamics study, J. Appl. Phys. 77 (7) (1995) 3121.

[40] T. Diaz de la Rubia, G.H. Gilmer, Structural transformations and defect production in ion implanted silicon: a molecular dynamics simulation study, Phys. Rev. Lett. 74 (13) (1995) 2507-2510.

[41] M.J. Caturla, L.A.M.T. Diaz de la Rubia, G.H. Gilmer, Ion-beam processing of silicon at keV energies: a molecular-dynamics study, Phys. Rev. B 54 (24) (1996) 16683-16695.

[42] K. Nordlund, M. Ghaly, R.S. Averback, M. Caturla, T. Diaz de la Rubia, J. Tarus, Defect production in collision cascades in elemental semiconductors and FCC metals, Phys. Rev. B 57 (13) (1998) 7556-7570

[43] R.S. Averback, T. Diaz de la Rubia, Displacement damage in irradiated metals and semiconductors, in: H. Ehrenfest, F. Spaepen (Eds.), Solid State Physics, 51, Academic Press, New York, (1998) 281-402.

[44] L. Pelaz, L.A. Marques, J. Barbolla, Ion-beam-induced amorphization and recrystallization in silicon, J. Appl. Phys. 96 (11) (2004) $5947-5976$.

[45] K. Nordlund, S. J. Zinkle, A. E.Sand, F. Granberg, R. S.Averback, R. E.Stoller, T. Suzudo, L. Malerba, F. Banhart, W. J. Weberh, F. Willaime, S. L. Dudarev, D. Simeone, Primary radiation damage: A review of current understanding and models, J. of Nucl. Mat., 512, (2018), 450-479.

[46] S. R. Messenger et al., Non ionizing energy loss (NIEL) for heavy ions, IEEE Trans. Nucl. Sci., 46 (6) (1999) 1595-1602.

[47] A. Akkerman et al. Updated NIEL calculations for estimating the damage induced by particles and gamma-rays in Si and GaAs, Rad. Phys. and Chem., 62, (2001) 301-310.

[48] I. Jun, W. Kim, and R. Evans, Electron nonionizing energy loss for device applications, IEEE Trans. Nucl. Sci., 56 (6) (2009) $3229-3235$.

[49] C. Inguimbert, and R. Gigante, NEMO: A code to compute NIEL of protons, neutrons, electrons, and heavy ions, IEEE Trans. Nucl. Sci., 53 (4) (2006) $1967-1972$. 
[50] M. J. Boschini et al., Nuclear and non-ionizing energy-loss for Coulomb scattered particle from low energy up to relativistic regime in space radiation environment, in Proc. the 12th ICATPP Conference on Astroparticle, Particle, Space Physics and Detectors for Physics Applications, Como, Italy, (2010) $9-23$.

[51] C. Inguimbert, and S. Messenger, Equivalent displacement damage dose for on-orbit space application, IEEE Trans. Nucl. Sci. 59 (6) (2012) $3117-3125$.

[52] C. Inguimbert, T. Nuns, D. Hervé, A. Vriet, J. Barbero, J. Moreno, A. Nedelcu, S. Ducret, O. Saint-Pé, F. Larnaudie, O. Gilard, C. Aicardi, Radiationinduced degradation of optoelectronic sensors, Proc. SPIE 11159, Electro-Optical and Infrared Systems: Technology and Applications XVI, 111590N (9 October 2019); doi: 10.1117/12.2532289

[53] H. Bichsel, Straggling in thin silicon detectors, Rev. Mod. Phys. 60, (1988) 663-699

[54] C. Inguimbert, T. Nuns, M. C. Ursule, D. Falguère, D. Hervé, M. Beaumel, M. Poizat, Image Sensors DCNU Modeling with GEANT4, IEEE Trans. Nucl. Sci., 61 (6) (2014) 3323-3330.

[55] M.C. Ursule, C. Inguimbert, T. Nuns, Impact of the border crossing effects on the DCNU for pixels arrays irradiated with high energy protons, IEEE Trans. Nucl. Sci., 63 (4) (2017) 2159-2167.

[56] M. C. Ursule, C. Inguimbert, T. Nuns,J. Morio, Comparison of Methods to Calculate the Dark Current Nonuniformity, IEEE Trans. Nucl. Sci. 65 (7) (2018) $1345-1354$.

[57] C. Inguimbert, S. Bourdarie, M. Beaumel, M. C. Ursule, R. Ecoffet, Inflight dark current non uniformity used for space environment model benchmarking, IEEE Trans. Nucl. Sci., 65 (8) (2018) 1676-1684.

[58] C.J. Dale, P.W. Marshall, E.A. Burke, G.P. Summers, and G.E. Bender, The Generation Lifetime Damage Factor and Its Variance in Silicon, IEEE Trans. Nucl. Sci. 36 (6) (1989) 1872-1881.

[59] P.W. Marshall, C.J. Dale, E.A. Burke, G.P. Summers, and G.E. Bender, Displacement Damage Extremes in Silicon Depletion Regions, IEEE Trans. Nucl. Sci., 36 (6) (1989) 1831-1839.

[60] P.W. Marshall, C.J. Dale, and E.A. Burke, Proton-Induced Displacement Damage Distributions and Extremes in Silicon Microvolumes, IEEE Trans. Nucl. Sci., 37 (6) (1990) 1776-1783.

[61] M.S. Robbins, High-Energy Proton-Induced Dark Signal in Silicon Charge Coupled Devices, IEEE Trans. Nucl. Sci., 47 (6) (2000) $2473-2479$.

[62] J. Bogaerts, B. Dierickx, and R. Mertens, Enhanced dark current generation in proton-irradiated CMOS active pixel sensors, IEEE Trans. Nucl. Sci., 49 (3) (2002) 1513-1521.

[63] R. Germanicus, S. Barde, L. Dusseau, G. Rolland, C. Barillot, F. Saigne, R. Ecoffet, P. Calvel, J. Fesquet, J. Gasiot, "Evaluation and prediction of the degradation of a COTS CCD induced by displacement damage," IEEE Trans. Nucl. Sci., 46 (6) (2002) 2830-2835.

[64] C. Virmontois V. Goiffon, P. Magnan,S. Girard, C. Inguimbert, S.Petit, G. Rolland, O.Saint-Pe Displacement damage effects due to neutron and proton irradiations on CMOS image sensors manufactured in deep sub-micron technology, IEEE Trans. Nucl. Sci., 57 (6) (2010) 3101-3108.

[65] GEANT4 - A simulation toolkit [Online]. Available : https://geant4.web.cern.ch/ Accessed January 27, 2020.

[66] K. Lemière, C. Inguimbert, and T. Nuns, Influence of a 3D Electric Field Enhancement Model on the Monte Carlo Calculation of the Dark Current in Pixel Arrays, accepted for publication into the J. of Appl. Phys. 128 (2020) 164502.

[67] ECSS 22900 Accessed: Jul. 14, 2020. [Online]. Available: http://escies.org/escc-specs/published/22900.pdf

[68] J. H. Warner, C. Inguimbert, M. E. Twigg, S. R. Messenger, R. J. Walters, M. J. Romero, G. P. Summers, Effect of Proton and Silicon Ion Irradiation on Defect Formation in GaAs, IEEE Trans.Nucl.Sci. 55 (6) (2008) 3016-3024.

[69] e2v. Accessed: Jul. 14, 2018. [Online]. Available online at: http://www.e2v-us.com/

[70] S. Katz, J. Barak, Energy spectra and LET spectra of protons behind shielding, Nucl. Instrum. Meth. B 333 (2014) 46-51.

[71] ASTM E722-14, Standard Practice for Characterizing Neutron Fluence Spectra in Terms of an Equivalent Monoenergetic Neutron Fluence for RadiationHardness Testing of Electronics, ASTM International, West Conshohocken, PA, 2014.

[72] I. Jun, M. Xapsos, S. R. Messenger, E. A. Burke, R. Walters, Proton non ionising energy loss (NIEL) for device applications, IEEE Trans. Nucl. Sci., (50) 62003 1924-1931.

[73] A. Akkerman, J. Barak, M. Murat, A Survey of the Analytical Methods of Proton-NIEL Calculations in Silicon and Germanium, in IEEE Trans. Nucl. Sci., 68 (8) (2020) 1813-1825. 